\title{
Estimation of Serum Vitamin D, Calcium and Phosphorus in Chronic Kidney Disease
}

\author{
Ajay Rajbhandari, Rajendra Kumar Agrawal, Anil Baral, Anil Pokhrel, Dineshwori Shrestha and Rajani \\ Hada
}

Department of Nephrology, National Academic of Medical Sciences, Bir Hospital, Kathmandu, Nepal

\begin{abstract}
Introduction: Abnormalities in mineral metabolism are invariable with progressive deterioration of kidney function in chronic kidney disease (CKD). These abnormalities are documented in CKD on dialysis in our population but not on pre dialysis. So, present study aims to estimate serum vitamin $\mathrm{D}$, calcium and phosphorus in CKD stage 3-5ND.

Methods: It was a cross sectional study of established new CKD patients not on dialysis, vitamin D, calcium, phosphate binders and corticosteroids therapy. Blood sample was drawn for estimation of serum vitamin D, creatinine, calcium, phosphorus and albumin and CKD staging done by KDIGO (2012) criteria. SPSS software version 19 was used for data analysis and chi-squared and ANOVA test was applied as the test of significance.

Results: Sixty six (51 male and 15 female) CKD patients with a mean age of $54.3 \pm 14.8$ years were studied. Hypovitaminosis D $(<30 \mathrm{ng} / \mathrm{ml})$ was present in $84.8 \%$, with deficiency $(<20 \mathrm{ng} / \mathrm{ml})$ in $50 \%$ and insufficiency $(20-30) \mathrm{ng} / \mathrm{ml}$ in $34.8 \%$. Other abnormalities observed were hypocalcemia (60.6\%), hypercalcemia (1.5\%) and hyperphosphatemia (63.6\%) with no difference of corrected calcium, significant difference of serum phosphorus $(\mathrm{p}<0.001)$ with hyperphosphatemia in stage 4 and $5 \mathrm{CKD}$ and vitamin D insufficiency in stage 3b, deficiency in stage 3a, 4 and $5 \mathrm{CKD}$. There was no correlation of serum vitamin $\mathrm{D}$ with calcium and phosphorus in different stages of CKD. Conclusion: Present study concludes that hypovitaminosis D, hypocalcemia and hyperphosphatemia is common in our pre-dialysis CKD patients and serum phosphorus raises more with reduction of GFR.

Keywords: chronic kidney disease; hypocalcemia; hyperphosphatemia; vitamin D
\end{abstract}

\section{INTRODUCTION}

Chronic kidney disease (CKD) is a modern day global epidemic with high cardiovascular morbidity and mortality. ${ }^{1}$ As kidney function declines, there is progressive and interrelated deterioration in mineral homeostasis with altered serum concentration of phosphorus, calcium, vitamin $\mathrm{D}$ and parathyroid hormone $(\mathrm{PTH})$, bone abnormalities, vascular and soft tissue calcification and finally increased cardiovascular disease. $^{2}$

Initially, transient retention of phosphorus, due to failing kidney, results decreased activity of renal 1a hydroxylase in proximal tubule with decreased calcitriol $\left(1,25 \mathrm{OH}_{2}\right.$ vitamin D) synthesis there by hypocalcaemia and compensatory hyperparathyroidism. But with advancing disease, the compensatory mechanism can no more maintain the mineral homeostasis and biochemical abnormalities like hyperphosphatemia, hypocalcaemia and hyperparathyroidism become obvious at stage $4 \mathrm{CKD}^{3,4}$ Besides, decreased kidney function, lack of adequate storage of vitamin $\mathrm{D}(25, \mathrm{OH}$ vitamin $\mathrm{D} /$ calcidiol $)$ is responsible for decreased calcitriol synthesis and its consequences in CKD. ${ }^{5}$ Studies have shown vitamin $\mathrm{D}$ deficiencies $(20-29 \mathrm{ng} / \mathrm{ml})$ and insufficiency $(<20 \mathrm{ng} / \mathrm{ml})$ in CKD, both in pre dialysis and maintenance hemodialysis patients,
This work is licensed under: http:// creativecommons.org/licenses/by-nc-nd/4.0/

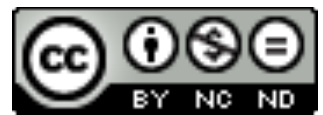

Correspondence: Ajay Rajbhandari, Department of Nephrology, National Academy of Medical Sciences, Bir Hospital, Kathmandu, Nepal. Email: rajbhandariajaya786@gmail.com 
probably due to its prevalence in general population or due to different factors related to CKD has predisposed low vitamin $\mathrm{D}$ level with its greater incidence in CKD compared to healthy control. ${ }^{6-8}$ Apart from calcitrophic effects, vitamin D has multiple beneficial effects in the body and hypovitaminosis D results in increased cardiovascular mortality in CKD as vitamin D supplementation in these patients had decreased cardiovascular risk with increased survival. ${ }^{6,9,10}$ Prevalence of hypovitaminosis D in $73.7 \%$ healthy Nepalese population and $89.1 \%$ patients with different health related problem were reported. ${ }^{11,12}$ But there is no reported study on status of vitamin D level and its calcitrophic and non calcitrophic effects in Nepalese CKD patients. So this is the first study of its kind carried out to find out the status serum vitamin $\mathrm{D}$ level and its relation with calcium and phosphorus in Nepalese pre-dialysis CKD patients.

\section{METHODS}

It was a hospital-based cross sectional study carried out in Department of Nephrology, National Academic of Medical Science (NAMS), Bir Hospital from June 2016 to August 2016 after approval by Institutional Review Board (IRB), NAMS. All consecutive pre-dialysis patients of stage 3-5ND (Non-Dialysis) were enrolled after taking informed written consent. Patients with age less than 18 years, acute on CKD, on hemodialysis, and those receiving vitamin $\mathrm{D}$ or its analogues, calcium supplements, phosphate binders and corticosteroids were excluded.

Pre-designed pro-forma was used for data collection. Patient's name, age, sex, history of hypertension and diabetes mellitus, blood pressure, height and weight were recorded. Then $10 \mathrm{ml}$ venous blood samples without tourniquet were drawn from each participant to estimate of serum creatinine, urea, albumin, calcium and phosphorus by Ebra Mannheim XL SysPack kit and vitamin D by automated Chemiluminescent Immunoassay technology. All data were first entered in the excel spread sheet for calculating different parameters and grouping of study population.

Estimated glomerular filtration rate (eGFR) was calculated by 2009 CKD Epidemiology Collaboration (CKD-EPI) creatinine equation. ${ }^{13}$ $\mathrm{CKD}$ staging was done according to KDIGO guidelines 2012 with eGFR $\left(\mathrm{ml} / \mathrm{min} / 1.73 \mathrm{~m}^{2}\right) 45$ 59 (stage 3a), 30-44 (stage 3b), 15-29 (stage 4) and $<15$ (stage 5$)^{14}$. Corrected calcium was calculated by using the equation-Corrected Calcium = measured $\mathrm{Ca}+0.8(4.0$ - albumin $){ }^{5}$

According to laboratory parameters the CKD patients were grouped in to vitamin D sufficient $(>30 \mathrm{ng} / \mathrm{ml}$ ), insufficient $(20$ to $30 \mathrm{ng} / \mathrm{ml})$ and deficient $(<20 \mathrm{ng} / \mathrm{ml})^{6}$ and corrected calcium $<8.5$ $\mathrm{mg} \%$ and $>10.5 \mathrm{mg} \%$ as hypocalcemia and hypercalcemia respectively, and serum phosphorus $<2.5 \mathrm{mg} \%$ and $>4.5 \mathrm{mg} \%$ as hypophosphatemia \& hyperphosphatemia respectively. ${ }^{15}$

Statistical analysis: Data analysis was performed by SPSS soft-ware package 19.0. Continuous variables were presented as mean+SD. ANOVA and Chi-square tests were applied as the test of significance and $p<0.05$ was taken as level of significance. Associations between vitamin D status and various stages of CKD were calculated by multivariate logistic regression analysis.

\section{RESULTS}

A total of sixty six patients were included in this study with male 51 (77.3\%) and female $15(22.7 \%)$ and age (mean $\pm \mathrm{SD}) 54.3 \pm 14.8$ years.

The distribution of patients in different CKD stages were stage $3 \mathrm{a}(15.2 \%)$, stage $3 \mathrm{~b}(37.9 \%)$, stage 4 $(22.7 \%)$ and stage 5ND (24.2\%) with significantly increasing serum creatinine and decreasing eGFR as shown in Table 1.

Analysis of serum corrected calcium, phosphorus and vitamin D showed no difference of corrected

Table 1: Frequency, serum creatinine and eGFR of subjects in different stages of CKD

\begin{tabular}{|c|c|c|c|}
\hline $\begin{array}{l}\text { CKD } \\
\text { stages }\end{array}$ & n $(\%)$ & $\begin{array}{c}\text { Serum } \\
\text { creatinine } \\
(\mathrm{mg} \%) \\
(\text { Mean } \pm \text { SD) }\end{array}$ & $\begin{array}{c}\text { eGFR } \\
(\mathrm{ml} / \mathrm{min} / \\
1.73 \mathrm{~m} 2) \\
(\text { Mean } \pm \mathrm{SD})\end{array}$ \\
\hline $3 \mathbf{a}$ & $10(15.2 \%)$ & $1.6 \pm 0.1$ & $48.7 \pm 3.5$ \\
\hline $3 \mathbf{b}$ & $25(37.9 \%)$ & $1.9 \pm 0.3$ & $37.4 \pm 5.2$ \\
\hline 4 & $15(22.7 \%)$ & $3.0 \pm 0.8$ & $22.5 \pm 4.7$ \\
\hline 5 & $16(24.2 \%)$ & $5.3 \pm 1.7$ & $11.3 \pm 2.6$ \\
\hline$p$ value & & 0.001 & 0.001 \\
\hline
\end{tabular}


Table 2: Biochemical parameters in different Stages of CKD

\begin{tabular}{|c|c|c|c|c|c|}
\hline $\begin{array}{l}\text { Variables } \\
(\text { Mean } \pm \text { SD) }\end{array}$ & $\begin{array}{l}\text { CKD Stage } 3 a \\
\qquad(\mathrm{n}=10)\end{array}$ & $\begin{array}{l}\text { CKD Stage 3b } \\
\qquad(\mathrm{n}=25)\end{array}$ & $\begin{array}{c}\text { CKD Stage } 4 \\
(\mathrm{n}=15)\end{array}$ & $\begin{array}{c}\text { CKD Stage } 5 \\
(n=16)\end{array}$ & $p$ value \\
\hline $\begin{array}{l}\text { Albumin } \\
\text { (gm/dl) }\end{array}$ & $4.1 \pm 0.8$ & $4.3 \pm 0.6$ & $4.3 \pm 0.4$ & $3.7 \pm 0.6$ & 0.021 \\
\hline $\begin{array}{c}\text { Calcium } \\
\text { (mg/dl) }\end{array}$ & $8.6 \pm 0.5$ & $8.6 \pm 0.9$ & $8.5 \pm 0.7$ & $8.0 \pm 0.8$ & 0.103 \\
\hline $\begin{array}{c}\text { Corrected Calcium } \\
(\mathrm{mg} / \mathrm{dl})\end{array}$ & $8.6 \pm 0.7$ & $8.4 \pm 0.7$ & $8.3 \pm 0.7$ & $8.3 \pm 0.7$ & 0.761 \\
\hline $\begin{array}{l}\text { Phosphorus } \\
\text { (mg/dl) }\end{array}$ & $4.1 \pm 0.8$ & $4.4 \pm 0.8$ & $5.4 \pm 0.9$ & $5.7 \pm 0.8$ & $<0.001$ \\
\hline $\begin{array}{c}25 \text { OH Vitamin D } \\
(\mathrm{ng} / \mathrm{mL})\end{array}$ & $16.9 \pm 4.8$ & $25.5 \pm 12.0$ & $18.4 \pm 9.1$ & $17.0 \pm 10.1$ & 0.026 \\
\hline
\end{tabular}

Table 3: Frequency distribution of subjects according to serum Vitamin $D$ level in different stages of CKD

\begin{tabular}{|c|c|c|c|c|c|}
\hline \multirow{3}{*}{ CKD stages } & \multicolumn{4}{|c|}{ Serum vitamin D (ng/ml) } & \multirow{3}{*}{ P value } \\
\hline & \multicolumn{3}{|c|}{ Low } & \multirow{2}{*}{$\begin{array}{c}\text { Normal } \\
\text { Sufficiency }\end{array}$} & \\
\hline & Deficiency & Insufficiency & Total & & \\
\hline $3 a(n=10)$ & 5 & 5 & $10(100 \%)$ & 0 & \multirow{5}{*}{0.136} \\
\hline $3 b(n=25)$ & 11 & 6 & $17(68 \%)$ & 8 & \\
\hline $4(n=15)$ & 8 & 6 & $14(93.3 \%)$ & 1 & \\
\hline 5 ND $(n=16)$ & 9 & 6 & $15(93.8 \%)$ & 1 & \\
\hline Total & $33(50 \%)$ & $23(34.8 \%)$ & $56(84.8 \%)$ & $10(15.2 \%)$ & \\
\hline
\end{tabular}

Table 4: Frequency distribution of subjects according to serum calcium level in different stages of CKD

\begin{tabular}{|c|c|c|c|c|c|c|}
\hline \multirow[t]{2}{*}{ Serum calcium (mg/dl) } & \multicolumn{4}{|c|}{ CKD stages } & \multirow[t]{2}{*}{ Total } & \multirow{2}{*}{ p-values } \\
\hline & $3 a$ & $3 b$ & 4 & $5 \mathrm{ND}$ & & \\
\hline$<8.5$ & $5(50 \%)$ & $14(56 \%)$ & $9(60 \%)$ & $12(75 \%)$ & $40(60.6 \%)$ & \multirow{4}{*}{0.555} \\
\hline $8.5-10$ & $5(50 \%)$ & $10(40 \%)$ & $6(40 \%)$ & $4(25 \%)$ & $25(37.9 \%)$ & \\
\hline$>10$ & 0 & $1(4 \%)$ & 0 & 0 & $1(1.5 \%)$ & \\
\hline Total & 10 & 25 & 15 & 16 & 66 & \\
\hline
\end{tabular}

calcium between different stages of CKD, significant difference of serum phosphorus $(\mathrm{p}<$ $0.001)$ with hyperphosphatemia in stage 4 and 5 $\mathrm{ND}$ and mean serum vitamin $\mathrm{D}<30 \mathrm{ng} / \mathrm{ml}$ in all stages of CKD with insufficiency in stage $3 \mathrm{~b}$ and deficiency in stage 3a, 4 and 5 (Table 2).

Grouping of the patients according to serum vitamin D, corrected calcium and phosphorus revealed hypovitaminosis D in $84.8 \%$

(insufficiency in 50\% and deficiency in $34.8 \%$ ), hypocalcemia in $60.6 \%$, hypercalcemia in $1.5 \%$ and hyperphosphatemia in $63.6 \%$. Further analysis of these parameters according to CKD stages had shown hypovitaminosis D in stage 3 a $(100 \%)$, stage $3 \mathrm{~b}(68 \%)$, stage $4(93.3 \%)$ and stage $5(93.8 \%)$ of patients with no statistical difference (Table 3). Similarly there was no difference of incidence of patients with normal and abnormal serum corrected 
Table 5: Frequency distribution of subjects according to serum phosphorus in different stages of CKD

\begin{tabular}{|c|c|c|c|c|c|c|c|}
\hline \multirow[t]{2}{*}{ Variables } & \multicolumn{5}{|c|}{ CKD stage } & \multirow{2}{*}{ Total } & \multirow{2}{*}{$p$ values } \\
\hline & $\mathrm{mg} / \mathrm{dl}$ & $3 a$ & $3 b$ & 4 & $5 N D$ & & \\
\hline \multirow{3}{*}{$\begin{array}{c}\text { Serum } \\
\text { Phosphorus }\end{array}$} & $>4.5$ & 3 & 10 & 14 & 15 & 42 & \multirow{3}{*}{$<0.001$} \\
\hline & $<4.5$ & 7 & 15 & 1 & 1 & 24 & \\
\hline & Total & 10 & 25 & 15 & 16 & 66 & \\
\hline
\end{tabular}

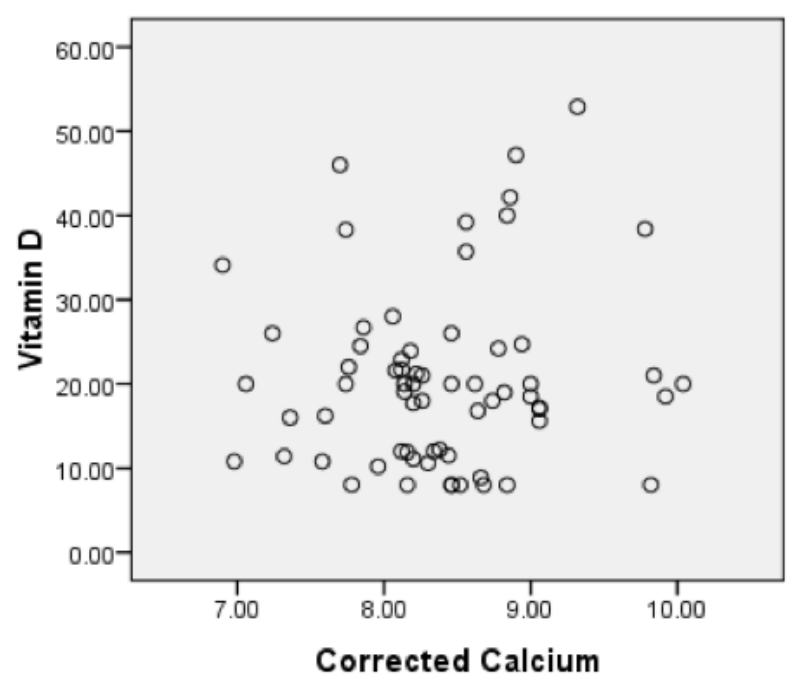

Figure 1: Showing no correlation between serum vitamin $\mathrm{D}$ and corrected calcium

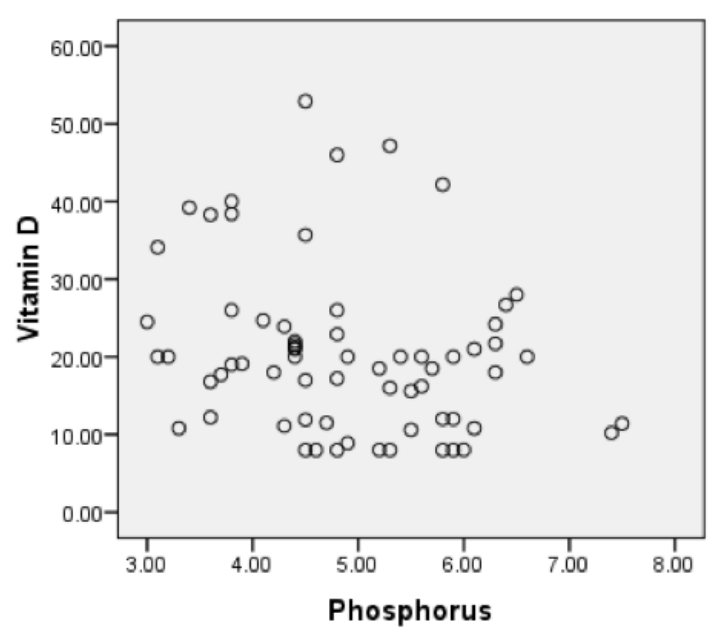

Figure 2: Showing correlation between serum vitamin D and phosphorus

calcium (Table 4) and significantly higher incidence of patients with hyperphosphatemia in stage $4(93.3 \%)$ and stage $5(93.8 \%)$ CKD (Table $5)$.

Pearson correlation coefficient study showed no correlation of serum vitamin $\mathrm{D}$ with eGFR ( $\mathrm{r}=$ $0.212, \mathrm{p}=0.087)$ and corrected calcium $(\mathrm{r}=0.096$,

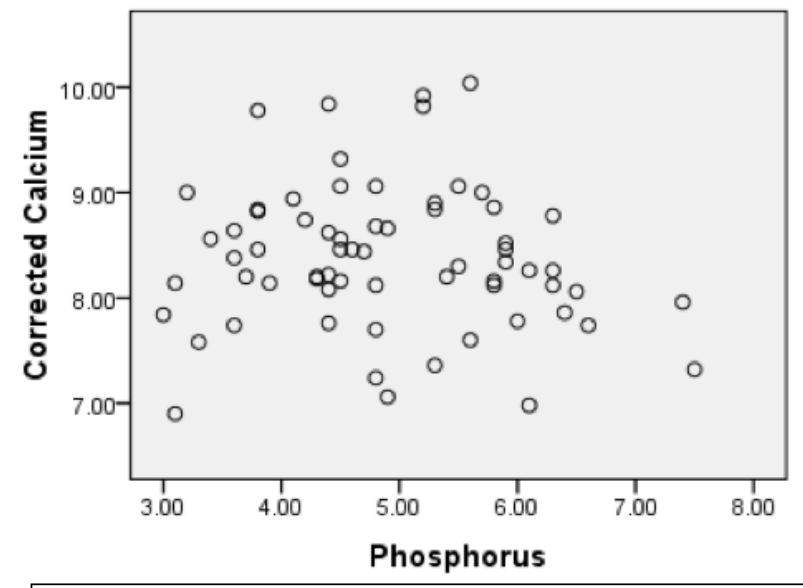

Figure 3: Showing no correlation of serum corrected calcium with phosphorus

$\mathrm{p}=0.443$, Fig 1) and significant negative correlation with phosphorus $(\mathrm{r}=-0.248, \mathrm{p}=0.045$, Fig 2). Serum phosphorus had significant negative correlation with eGFR $(r=-0.6, p<0.001)$ and no correlation with corrected calcium $(\mathrm{r}=-0.109, \mathrm{p}=$ 0.385 , Fig 3 ).

\section{DISCUSSION}

This is the first study conducted to estimate serum vitamin $\mathrm{D}$, calcium and phosphorus in pre dialysis CKD patients in Nepalese population. It has shown high prevalence of hypovitaminosis D (84.8\%), hypocalcemia $(60.6 \%)$ and hyperphosphatemia $(63.6 \%)$ in these patients. Low vitamin D level is related to inadequate exposure to sunshine and dietary deficiencies in general population and correlated with multiple diseases including bone metabolism and calcium hemostasis. ${ }^{9}$ It is also common in CKD and reported from different geographical regions with $100 \%$ in Malaysia ${ }^{16}$, $72.7 \%$ in Thailand ${ }^{17}, 90.4 \%$ in Northen India ${ }^{18}$, $86 \%$ in Southern India ${ }^{19}$ and $73.6 \%$ in Brazil. ${ }^{20}$

Comparative studies on status of vitamin D in CKD and healthy control had shown high and equivalent 
prevalence of hypovitaminosis $\mathrm{D}^{7,16}$ and supported the possibility of this condition in CKD due to its presence in population whereas other reports with greater prevalence of this condition in CKD has postulated the possibility of factors related to CKD itself could have resulted this condition. 6,8 Moreover, severity of hypovitaminosis was found to be more with decreasing kidney function with most severe condition in stage $5 \mathrm{CKD}^{17,19,21}$ but others have shown no influence of eGFR on serum vitamin D level with similar finding in all stages of CKD. ${ }^{20}$ In our study, patients were in stage $3 a, 3 b$, 4 and 5 CKD with mean serum vitamin D level in the range of insufficiency in stage $3 \mathrm{~b}$ and deficiency in remaining stages with no significant difference and $68 \%$ of stage $3 b, 100 \%$ of stage $3 a$ and $>93 \%$ of stage 4 and 5 had hypovitaminosis D showing no influence of kidney function on serum vitamin D level. Correlation analysis of eGFR with serum vitamin $\mathrm{D}$ also showed no linear relationship $(\mathrm{r}=0.212, \mathrm{p}=0.086)$. Moreover, Nepal lies in temperate zone and low vitamin $\mathrm{D}$ is highly prevalent in Nepalese healthy people ${ }^{11}$, hypovitaminosis in our cohort could have reflected its prevalence here rather than the effect of CKD on vitamin $\mathrm{D}$ and further comparable studies on status of vitamin $\mathrm{D}$ in CKD and healthy control along with their dietary status will verify these findings.

Hypocalcemia is a part of abnormal mineral metabolism in CKD and becomes obvious from stage $4 \mathrm{CKD}^{3,4}$. Hypocalcemia is mainly due to decreased absorption from intestine secondary to inadequate vitamin $\mathrm{D}$ and deposition of calcium and phosphorus product in bone secondary to hyperphosphatemia in CKD. ${ }^{22}$ Reports on incidence and severity of hypocalcemia in CKD are variable. It was found in $23.8 \%$ of CKD from stage 3 to $5 \mathrm{D}$ in a tertiary care center in North India with significant difference in different stage of CKD and affected $25.1 \%$ of stage 3 and $32.1 \%$ of stage $5 \mathrm{ND}$. 18 Other studies from Thailand had shown normal mean serum corrected calcium level in CKD stage 2 to 4 with no significant difference by Chartsrisak et $\mathrm{al}^{22}$ and normal but significantly lower calcium (in CKD stage $4 \& 5$ compared to stage $3 a$ ) and (in patients with vitamin $\mathrm{D}$ deficient compared to sufficient) by Sitarapoj et al. ${ }^{17}$ Reports had shown variable relation of serum calcium with vitamin D with no association ${ }^{21}$ and significantly low calcium in patients with low vitamin D. ${ }^{17}$
In present study, although mean serum corrected calcium was within normal limit only in stage $3 \mathrm{a}$ patients and remaining had mild hypocalcemia, the number of patients with low serum calcium had increased progressively with increasing CKD stages with $50 \%$ in stage 3 a to $75 \%$ in stage 5 with no association of serum calcium with serum phosphorus and vitamin $\mathrm{D}$ in all stages of CKD indicating dietary deficiency or inadequate calcitriol synthesis by failing kidney could have played role in reduced calcium level. Further comparable studies of serum calcium in CKD and healthy control from same socioeconomic background are essential to verify these findings.

Hyperphosphatemia is the independent predictor of increased cardiovascular mortality ${ }^{23}$. High prevalence of hyperphosphatemia in pre-dialysis CKD has been reported from different parts of the world with $69.4 \%$ in Nigeria $^{8}$ and $53.7 \%$ to $64.1 \%$ in India ${ }^{18}$. Contrary to serum calcium, serum phosphorus showed gradual increment with rise of CKD stage indicating inverse relation with eGFR 18,21,22 Similarly, we also found hyperphosphatemia in $63.6 \%$ patients and mean phosphorus level gradually increased with increasing CKD stage with significant negative correlation with eGFR $(r=-0.6, p<0.001)$. Serum phosphorus level remained within normal limit in stage $3 a$ and $3 b$ and become high in stage 4 and 5ND indicating phosphorus hemostasis could no more be maintained once eGFR is $<30 \mathrm{ml} / \mathrm{min}$ even in our cohort. Moreover, hyperphosphatemia causes reduced synthesis of calcitriol and secondary hyperparathyroidism which causes increased degradation of vitamin D with decreased substrate for calcitriol synthesis ${ }^{5}$. Although direct effect of serum phosphorus on vitamin D is not well known, inverse relation of serum phosphorus and vitamin $\mathrm{D}$ in CKD has been documented in several studies ${ }^{17,21}$ including in our patients.

\section{CONCLUSIONS}

Hypovitaminosis D, hypocalcemia and hyperphosphatemia are common in pre-dialysis CKD patients with no difference of incidence of hypovitaminosis and hypocalcemia in different stages of CKD. There is significantly higher incidence of hyperphosphatemia with decreasing eGFR and increasing CKD stages. 


\section{REFERENCES}

1. Yuan J, Zou XR, Han SP, Cheng H, Wang L, Wang JW et al. Prevalence and risk factors for cardiovascular disease among chronic kidney disease patients: results from the Chinese cohort study of chronic kidney disease (C-STRIDE). BMC Nephrology 2017;8:23. https:// doi.org/10.1186/s12882-017-0441-9

2. Cozzolino $M$, Ureña-Torres $P$, Vervloet $M G$, Brandenburg V, Bover J, Goldsmith D et al. Is chronic kidney disease-mineral bone disease (CKD-MBD) really a syndrome? Nephrol Dial Transplant 2014;29:1815-20. https://doi.org/10.1093/ndt/gft514

3. Cunningham J, Locatelli F,Rodriguez M. Secondary hyperparathyroidism: pathogenesis, disease progression and therapeutic options. Clin J Am Soc Nephrol 2011;6:913-921. doi: 10.2215/CJN.06040710.

4. Levin A, Bakris GL, Molitch M, Smulders M, Tian J, Williams LA et al. Prevalence of abnormal serum vitamin D, PTH, calcium, and phosphorus in patients with chronic kidney disease: results of the study to evaluate early kidney disease. Kidney International 2007;71:31-38. doi:10.1038/sj.ki.5002009

5. Nigwekar SU, Tamez H, Thadhani RI. Vitamin D and chronic kidney disease-mineral bone disease (CKDMBD). BoneKEy Reports 3, Article number: 498 (2014) | doi:10.1038/bonekey.2013.232

6. Jean G, Souberbielle JC and Charles Chazot C. Vitamin D in Chronic Kidney Disease and Dialysis Patients. Nutrients 2017; 9: 328. doi:10.3390/nu9040328

7. Guessous I, McClellan,W, Kleinbaum, D, Vaccarino V, Zoller O, Theler JM et al. Comparisons of serum vitamin D levels, status, and determinants in populations with and without chronic kidney disease not requiring renal dialysis: A 24-h urine collection population-based study. J. Ren. Nutr. 2014; 24: 303-312. doi: 10.1053/ j.jirn.2014.04.005

8. Okoye JU, Arodiwe EB, Ulasi II, Ijoma CK, Onodugo OD. Prevalence of CKD-MBD in pre-dialysis patients using biochemical markers in Enugu, South-East Nigeria. Afri Health Sci 2015;15(3):941-8. doi: http:// dx.doi.org/10.4314/ahs.v15i3.31

9. Holick MF. Vitamin D deficiency. N Engl J Med. 2007;357:266-81. https://doi.org/10.1056/ $\underline{\text { nejmra070553 }}$

10. Lishmanov A, Dorairajan S, Pak Y, Chaudhary K, Chockalingam A. Treatment of $25-\mathrm{OH}$ vitamin D deficiency in older men with chronic kidney disease stages 3 and 4 is associated with reduction in cardiovascular events. Am J Ther 2011; PMID: 22185755 ; http://dx.doi.org/10.1097/MJT. $\underline{0 \mathrm{~b} 013 \mathrm{e} 3182211 \mathrm{~b} 3 \mathrm{~b}}$
11. Bhatta MP, Pandey BP, Gurung KM, Nakarmi R, Gurung K, Gurung LB et al. Prevalence of vitamin D deficiency among adult population of Western Region of Nepal. International Journal of Medicine \& Biomedical Sciences.2016;1(2):7-12.

12. Shrestha S, Shrestha L and Jha DK. Vitamin D status among individuals attended in Health Home Care Centre, Lalitpur, Nepal. Nepal Med Coll J. 2012;14(2): 84-87.

13. Stevens LA, Claybon MA, Schmid $\mathrm{CH}$, Chen J, Masaru Horio M, Imai E,Robert $G$ et al. Evaluating CKD-EPI for eGFR in multiple ethnicities (Evaluation of the Chronic Kidney Disease Epidemiology Collaboration equation for estimating the glomerular filtration rate in multiple ethnicities). Kidney International 2011;79:555-562. doi:10.1038/ki. 2010.462;

14. KDIGO 2012 Clinical Practice Guideline for the Evaluation and Management of Chronic Kidney Disease. Kidney International Supplements 2013;3:19-62. doi: 10.1038/kisup.2012.64

15. KDIGO Clinical Practice Guideline for the Diagnosis, Evaluation, Prevention, and Treatment of Chronic Kidney Disease-Mineral and Bone Disorder (CKD-MBD). Kidney International 2009;76 (Suppl 113): S22-S49. doi:10.1038/ki.2009.191

16. Rozita M, Afidza MN, Ruslinda M, Cader R, Halim AG, Kong CTN et al.Serum vitamin D levels in patients with chronic kidney disease. EXCLI Journal 2013;12:511-520 - ISSN 1611-2156.

17. Satirapoj B, Limwannata P, Chaipraser A, Supasyndh O, Choovichian P. Viatmin D insufficiency and deficiency with stages of chronic kidney disease in an Asian population. BMC Nephrol. 2013 Oct 2;14:206. doi: 10.1186/1471-2369-14-206.

18. Vikrant S, Parashar A. Prevalence and severity of disordered mineral metabolism in patients with chronic kidney disease: A study from a tertiary care hospital in India. Indian J Endocr Metab 2016;20:460-7. doi: $10.4103 / 2230-8210.183457$

19. Arulanantham R, Mariappari S, Radhakrishnan S. Prevalence of vitamin $\mathrm{D}$ deficiency in chronic kidney disease: A single centered study from a rural tertiary care hospital in South India. J. Evid. Based Med. Healthc. 2016;3(22): 978-982. doi: 10.18410/jebmh/2016/224

20. Diniz HF, Romão MF, Elias RM, Júnior JER. Vitamin D deficiency and insufficiency in patients with chronic kidney disease. J Bras Nefrol 2012;34(1):58-63.

21. Valencia CAR, Arango JVA. Vitamin D (25(OH)D) in patients with chronic kidney disease stages 2-5.Vitamin D $(25(\mathrm{OH}) \mathrm{D})$ in patients with chronic 
kidney disease stages 2-5.Colomb Med (Cali) 2016;47(3); 160-166. PMC509127.

22. Chartsrisak K, Vipattawat K, Assanatham M, Nongnuch $\mathrm{A}$, Ingsathit $\mathrm{A}$, Domrongkitchaiporn $\mathrm{S}$ et al. Mineral metabolism and outcomes in chronic kidney disease stage 2-4 patients. BMC Nephrology 2013;14:14. https://doi.org/10.1186/1471-2369-14-14

23. Shaman AM, Kowalski. Hyperphosphatemia management in chronic kidney disease. Saudi Pharmaceutical Journal (2016) 24, 494-505. 